\title{
Timing of Surgery for a Tibial Pilon Fractures - Search for a Wise Moment
}

\author{
Ilir Hasani* \\ University Clinic for Traumatology, Orthopaedic Diseases, Anaesthesia, Reanimation, Intensive Care and Emergency Centre \\ - Skopje, Ss Cyril and Methodius University of Skopje, Skopje, Republic of Macedonia
}

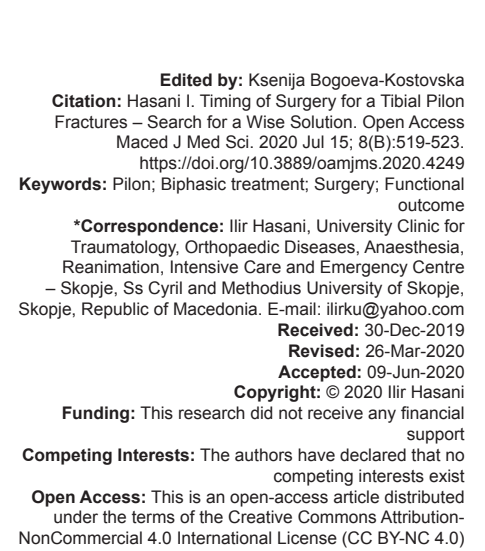

Abstract

BACKGROUND: Biphasic treatment of pilon fractures has been accepted as standard modality of care.

AIM: The aim of the present study was to evaluate the effect of timing of definitive surgery for closed pilon fractures on the short-term functional outcome.

MATERIALS AND METHODS: Prospective study focused the patients suffering pilon fracture that has undergone treatment in a biphasic manner. Initially, spanning external fixator was applied, while the definitive osteosynthesis was performed within the next several days, in accordance with surgeon's knowledge. The final functional outcome was evaluated using the American Orthopedic Foot and Ankle Society Ankle-Hindfoot Score.

RESULTS: Forty-two patients were included in the study. Mean time passed from injury to definitive surgery was 11.0 \pm 3.4 days. Mean value of the functional score was $86.54 \pm 13.2$ points, with no significant differences with regard to the demographics and injury features. Pearson correlation coefficient demonstrated negative significant correlation between timing of definitive surgery and functional outcome $(r=-0.428, p=0.033)$. Complications were noted in $16 \%$ of the patients.

CONCLUSION: Definitive surgery should be planned as soon as possible, once the surgeon considers the soft-tissue status acceptable for surgery. Injudicious postponing has a negative effect on the short-term functional outcome.

\section{Introduction}

Since first description of the operative treatment of pilon fractures by Lambotte, these fractures have gained the reputation of notoriously difficult injuries, for both the surgeon and the injured [1]. So far, great scientific volume focused on the fractures of the tibial pilon has been published, and it seems that the interest is still growing. Representing only $1 \%$ of all fractures, they affect individuals of all age groups; in the younger, they are most commonly caused by high-energy transfer, while in the elderly, as a low-energy mechanism [2]. Following this injury, high percentage of complications has been consistently reported, including nonunion and malunion, as well as infection, soft-tissue necrosis, and post-traumatic arthritis [3], [4], [5].

Initial disappointment of both operative and non-operative treatment of pilon fractures in the mid- $20^{\text {th }}$ century was followed by the establishment of $\mathrm{AO}$ principles that had traced the way of the modern treatment of pilon fractures [6], [7], [8], [9], [10], [11]. Namely, the AO principles were focused on open reduction and anatomical fixation with absolute stability of the articular fractures. While these principles revolutionized the treatment of articular skeletal injuries in general, the result of the treatment of pilon fractures remained less satisfactory, primarily due to the complications originating from the soft tissues. The care of the softtissue coverage which had been demonstrated to be a crucial component of the pilon injuries, had changed the way of thinking of the skeletal surgeons and led to the development of limited approaches, including hybrid external fixation, and use of external fixation method, as described by llizarov, and percutaneous screw fixation [12], [13], [14], [15], [16], [17]. While preserving the soft tissues, these techniques could not achieve anatomical reduction and absolute stability of the articular surface, which had been shown to be not only beneficial but also more of the necessity for articular fractures. For these reasons, further development of the treatment modalities encompassed the use of the biphasic timing of surgery, minimally invasive approaches and use of modern locking implants.

In a search for the best possible solution for those suffering these challenging-to-treat injuries, we were motivated to design and conduct a single-center prospective study. The aim of the present study was to evaluate the effect of timing of definitive surgery for closed pilon fractures on the short-term functional outcome in those suffering these notoriously serious injuries. 


\section{Materials and Methods}

A prospective nonrandomized study was conducted at the University clinic of Trauma in Skopje in a period of 2 years (January 2015-December 2017), on consecutive patients with pilon fractures operatively treated at the Institution. Inclusion was focused on the patients older than 16 years of age, closed fractures type I or II according to the classification system of Tscherne and Oestern, and subtypes 1 or 2 of $\mathrm{AO} /$ ASIF $B$ or $C$ types that have undergone minimally invasive percutaneous treatment with a locking plate in a biphasic manner. According to the Tscherne and Oestern classification system of soft-tissue injury in closed fractures, type $\mathrm{CO}$ refers to the fractures with minimal or no soft-tissue injury, type $\mathrm{C} 1$ refers to the superficial abrasions and contusions, type C2 denotes deep abrasions or impending compartment syndrome, while type C3 denotes extensive skin contusion, myonecrosis, degloving, vascular injury, or compartment syndrome [18]. According to AO classification system, type $\mathrm{B}$ denotes partial articular fracture and type C complete articular fracture; subtype 1 refers to the absence of impaction and comminution, and subtype 2 denotes impaction and comminution present. Exclusion criteria included American Society of Anesthesiology Score of 5, presence of concomitant skeletal or visceral injury requiring surgical treatment and poor and very poor reduction as evaluated by Teeny and Wiss score on the X-rays taken post definitive surgery [19].

\section{Diagnostic and treatment protocol}

Following the presentation at the emergency department, in those with a suspected fracture, splint was applied and plain X-rays were undertaken. In those in whom pilon fracture was present, the biphasic treatment was initiated. Initial component of the treatment referred to the application of the spanning external fixator within $1^{\text {st }}$ several hours following the injury. The spanning external fixator was applied in accordance with the well-established AO principles and fibular fracture was reduced and fixed with either tubular plate or intramedullary rod [20]. The procedure is undertaken under spinal anesthesia and with single dose antibiotic prophylaxis. For the next several days, the patients remained in the hospital for close checkups of the extremity, thromboprophylaxis, and early mobilization. In this phase, high-quality multiplanar computed tomography (CT) scans of the pilon were undertaken. Based on the CT scans, we defined the fracture classification, degree of comminution, impaction, and intra-articular involvement. We planned definitive surgery closely keeping in mind all these components. The definitive surgery was performed once the condition of the skin and underlying soft-tissues has recovered and the edema has subsided; all the patients were checked for the "wrinkle sign" as a reliable clinical indicator for the condition of the soft-tissue coverage [21].

Definitive surgery was undertaken under spinal anesthesia using the technique of minimally invasive percutaneous plate osteosynthesis. The surgical procedure starts with the removal of the external fixator. Distal incision on the medial or lateral side of the leg is performed, depending on the site of more pronounced comminution, which allows for direct visualization and reduction of the intra-articular component of the fracture. Once distal incision has been made, wide raspatory is advanced proximally in a submuscular plane, thus creating a tunnel in which the plate will be positioned. In certain cases, the plate itself can be used as an raspatory. The placement of the upper incision is planned with plate as a template. The plate is compressed on the skin for several seconds, following which the margins of the plate are temporarily delineated onto the skin. In that way, the upper incision is planned; sometimes, separate stab incisions are necessary to position the locking screws in a proper manner.

Fixation of the distal tibia is performed with anatomical plates in which distal screws are placed in a locking manner, while for proximal fixation; the holes are combined, for locking, and cortical screws. The fracture of the fibula can be addressed during the initial phase, or in the definitive phase, and it can be fixed with a conventional plate, locking plate, intramedullary nail, or it can be left unfixed, depending on the level and type of the fracture.

\section{Post-operative protocol}

Early rehabilitation starts on the $1^{\text {st }}$ or $2^{\text {nd }}$ post-operative day, once surgical drains have been removed, if present. Verticalization is aided by crutches or walker depending on the general condition of the patient. Once the patient has been verticalized and the wound has been checked for the signs of early postoperative complications, the patient is dismissed from the hospital and advised to continue the rehabilitation protocol. The stitches are removed 14 days following the surgery and outpatient checkups are performed in a period of 1 month, 3 months, 6 months, and a year post-injury. Thromboprophylaxis is continued for 4 weeks. The patients are encouraged to start partial weight-bearing 6-8 weeks post-surgery and gradually convert to full weight bearing in a period of 2-3 months post-surgery.

\section{Study protocol and enrollment of the patients}

Initially, the study was approved by the ethical board of the hospital. The patients that were admitted to the hospital for the treatment of pilon fracture were examined by the first author, and those who met 
the inclusion and exclusion criteria and were willing to take part in the study were included just before hospital discharge. Namely, they were approached by the author, who explained them the nature and the purpose of the study and gave them the opportunity to ask questions. Once the patient signed the informed consent, all the necessary data were collected in a case report form that was stored in an Excel file. These data included demographics, mechanism, and type of injury type of fracture and degree of soft-tissue injury as graded by $\mathrm{AO}$ classification and Tscherne and Oestern classification, respectively, timing and duration of initial and definitive surgery, technical details of the treatment including type of osteosynthesis and early postoperative complications. In all the patients, previously described post-operative protocol was followed. At the final follow-up which was a year post-surgery, the functional outcome was recorded, as evaluated by American Orthopedic Foot and Ankle Society Ankle-Hindfoot Scale (AOFAS). It is a clinician-based questionnaire which consists of three groups of questions: Pain (maximum of 40 points), function (maximum of 50 points), and alignment (maximum of 10 points). The maximum possible score counts 100; the questions related to pain and function are answered by the patients, while the alignment is evaluated by the examiner. In this study, the questionnaire was completed by the surgeon that was not involved in the treatment.

\section{Statistical analysis}

Once the study was completed, all data that were initially collected and stored in an Excel file were transferred to the software for statistical analysis (SPSS, version 23.0). Categorical data were analyzed and presented as absolute and relative numbers, while for the quantitative data; descriptive parameters were used (mean $\pm \mathrm{SD}$, median, minimum, and maximum). The correlation between the time of the definitive surgery and the functional score was analyzed by the Pearson correlation coefficient. Values of $p<0.05$ were considered as statistically significant.

\section{Results}

\section{General characteristics, demographics, and mechanism of injury}

In a period of 2 years, total of 51 patients met the inclusion and exclusion criteria and were enrolled in the study. During the follow-up period, one patient died from the injuries of another accident, two were excluded because of the implant failure before bone healing, two were uncompliant, and four were unavailable at the final outpatient follow-up. Of those 42 (82\%) who finished the study, there was male predominance (28 patients, $66.6 \%$ ). Mean age of the whole study group was 48 \pm 15.3 years, with a range of $24-76$ years and almost equal mean values in males and females. With regard to the mechanism of injury, in 31 patients $(74 \%)$, the pilon fracture was consequence of high-energy trauma (motor-vehicle accident in all of them); in the remaining 11 patients $(26 \%)$, it was low-energy trauma that resulted in pilon fracture. In seven patients $(16.6 \%)$ concomitant injuries were noted, none of them requiring surgical treatment. No bilateral injuries were noted.

\section{Characteristics of the injury}

All the fractures were classified according to the AO classification system. In 19 patients, type B fracture was present (B1 in 10 and B2 in 9 patients), while in the remaining 23 patients (54.7\% of the study group) type C fractures were diagnosed (14 patients with type C1 and 9 patients with type C2). The degree of soft-tissue injury was measured by the classification system of Tscherne and Oestern, and we found type I injury in 24 patients $(57 \%)$ and type II injury in 18 patients.

\section{Final follow-up, AOFAS score, timing of} definitive surgery, and complications

At the final follow-up, a year post-injury, functional outcome was evaluated by the AOFAS score. Mean value of the score for the whole study group was $86.54 \pm 13.2$ points. We found no statistically significant differences when mean scores were compared by groups formed with regard to the mechanism of injury, fracture type, and the degree of soft tissue injury. We recorded the time passed from injury - initial surgery to definitive surgery, and the results showed mean time of $11.0 \pm 3.4$ days. To correlate between the timing of definitive surgery (time between injury and definitive surgery, expressed in days) and final functional outcome, Pearson correlation coefficient was analyzed. The Pearson correlation coefficient (Figure 1) demonstrated negative significant correlation

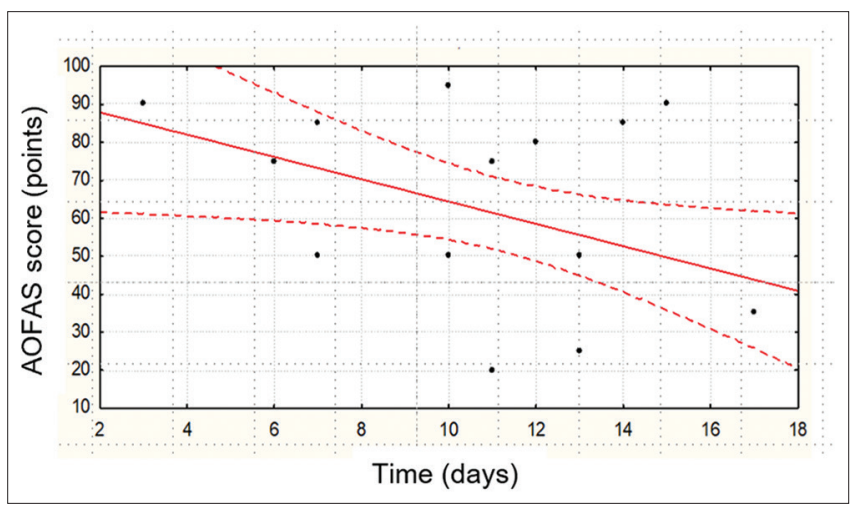

Figure 1: Pearson correlation coefficient - horizontal axis refers to the time passed from initial surgery to definitive surgery, while on the vertical axis, American Orthopedic Foot and Ankle Society Ankle-Hindfoot Scale values are presented 
between the variables analyzed $(r=-0.428, p=0.033)$. Complications were noted in $16 \%$ of the study group (seven patients), including superficial surgical site infection in three patients, Südeck dystrophy in two patients, pseudarthrosis in one patient, and malunion in one patient.

\section{Discussion}

Our results demonstrated very good short-term functional outcome following operative treatment in a biphasic manner of $\mathrm{B} 1$ and $\mathrm{B} 2$, as well as $\mathrm{C} 1$ and $\mathrm{C} 2$ pilon fractures. In the seminal work of Rüedi and Allgöwer, the authors reflected on a long history of the treatment of intra-articular fractures of tibial pilon, concluded that for many years, these injuries were considered as not amenable to surgery, while poor outcome was, simply, a matter of bad luck [7]. Following this statement as an introduction, they described a study of 75 patients with pilon fractures in a mean follow-up of 6 years. They reported on superior results in those treated with open reduction and internal fixation, compared to those treated by non-operative means. In addition, they summarized that these injuries are "an interesting challenge." Since then, increasing number of practicing surgeons started to operate on pilon fractures respecting the principles established by Rüedi and Allgöwer [7]. The study of Dillin et al. reported on a group of only 11 patients with high-energy pilon fractures, and concluded that degree of comminution and the severity of soft-tissue injury should be taken into consideration when deciding on operative treatment [22]. Similarly, yet another study reported on high post-operative complications originating from the soft-tissue envelope and concluded that external fixation gives satisfactory results and fewer complications when compared to internal fixation [23]. Quite a number of studies reported on similar results, leading to conclusion that high-energy injuries resulting in severe soft-tissue damage were joined with a high rate of complications (mainly infection) related to the soft tissues injury [6], [19].

In 1999, the results of the 21 retrospectively collected patients with pilon C3 type fracture treated with a staged protocol were published [24]. Initially, spanning external fixator had been applied, after which, external fixator was removed and formal open reduction and internal fixation of the pilon fracture was performed. The time passed between two surgeries was an average of 24 days. The authors concluded that two-staged approach offers acceptable results for severe pilon fractures and reported no complications originating from the soft tissues or infection. Concurrently but independently, Sirkin and his associates also published the results of 48 patients with type $\mathrm{C}$ pilon fractures treated with a staged protocol [25]. Interestingly, their results demonstrated only one case of infection out of 29 patients with a closed fracture. Following these preliminary results of the staged protocols, several authors reported encouraging results, which led to its wide acceptance by the practicing surgeons [26], [27], [28].

In the present study, we focused on the time passed between the initial fracture stabilization and definitive surgery. The so-called "wrinkle sign" is widely accepted clinical indicator for the condition of the soft tissues [29]. Namely, most of the surgeons use this clinical sign to determine the term of the definitive surgery. However, its real importance has not been scientifically studied. For that reasons, we were motivated to examine the time expressed in days between the two surgeries. Interestingly but not surprisingly, the results demonstrated that postponing the surgery lead to unfavorable functional outcome. From the practical point of view, the definitive surgery should not be postponed indefinitely; in should be performed once swelling has subsided and soft-tissue condition allows for surgery. Unreasonable postponing leads to worse outcome, increased health-care costs and prolonged hospital stay.

Our study has a number of limitations. It includes a small number of patients driven from a single institution. Furthermore, follow-up period is quite short, and we lack a control group. However, the prospective nature of the study, quite strict inclusion and exclusion criteria and high attendance rate were the positive sides.

\section{Conclusion}

Postponing the definitive surgery in pilon fractures following initial spanning is clearly beneficial. However, the timing of definitive surgery should be planned in accordance with the conditions of the softtissue coverage. Definitive surgery should be planned as soon as possible, once the surgeon considers the soft-tissue status acceptable for surgery. Injudicious postponing has a negative effect on the short-term functional outcome.

\section{References}

1. Peltier LF. Fractures-history and Iconography of their Treatment San Francisco: Norman Publishing; 1990.

2. Court-Brown CM, Caesar B. Epidemiology of adult fractures: A review. Injury. 2006;37:691-7. PMid:16814787

3. Borrelli J Jr, Ricci WM. Acute effects of cartilage impact. Clin Orthop Relat Res 2004;423:33-9. 
PMid:15232423.

4. Bourne RB. Pylon fractures of the distal tibia. Clin Orthop Relat Res. 1989;240:42-6.

PMid:2917444

5. Ries MD, Meinhard BP. Medial external fixation with lateral plate internal fixation in metaphyseal tibia fractures. A report of eight cases associated with severe soft-tissue injury. Clin Orthop Relat Res. 1990;256:215-23. https://doi. org/10.1097/00003086-199007000-00031

PMid:2364610

6. Bourne RB, Rorabeck CH, Macnab J. Intra-articular fractures of the distal tibia: The pilon fracture. J Trauma. 1983;23(7):591-6. https://doi.org/10.1097/00005373-198307000-00008

\section{PMid:6876212}

7. Rüedi TP, Allgöwer M. The operative treatment of intra-articular fractures of the lower end of the tibia. Clin Orthop Relat Res. 1979;138:105-10.

PMid:376196

8. Etter C, Ganz R. Long-term results of tibial plafond fractures treated with open reduction and internal fixation. Arch Orthop Trauma Surg. 1991;110(6):277-83. https://doi.org/10.1007/ bf00443458

9. Müller ME, Allgöwer M, Schneider R, Willenegger H. Manual of Internal Fixation Techniques Recommended by the AO Group. NewYork: Springer-Verlag; 1979. p. 146-7, 208-10, 214-5, 586612. https://doi.org/10.1007/978-3-642-96505-0

10. Müller ME, Algöwer M, Willenegger $\mathrm{H}$. Technik der Operativen Frakturbehandlung. NewYork: Springer-Verlag Berlin Heidelberg GMBH; 1963.

11. Sitnik A, Beletsky A, Schelkun S. Intra-articular fractures of the distal tibia: Current concepts of management. EFORT Open Rev. 2017;2(2):352-61. https://doi.org/10.1302/2058-5241.2.150047 PMid:28932487

12. Atkins RM, Sudhakar JE, Porteous AJ. Use of modified Ilizarov olive wires as pushing wires. J Orthop Trauma. 1998;12(6):4368. https://doi.org/10.1097/00005131-199808000-00014 PMid:9715454

13. Hutson JJ, Zych GA. The Treatment of 100 Tibia/Fibula, Distal Segment (43) Fractures with Circular Tensioned Wire Fixators. San Antonio, Texas: $16^{\text {th }}$ Annual Meeting of the Orthopaedic Trauma Association; 2000. https://doi. org/10.1097/00005131-200008000-00005

14. Kim HS, Jahng JS, Kim SS, Chun $\mathrm{CH}$, Han HJ. Treatment of tibial pilon fractures using ring fixators and arthroscopy. Clin Orthop Relat Res. 1997;334:244-50. https://doi. org/10.1097/00003086-199701000-00031 PMid:9005919

15. Watson JT, Moed BR, Karges DE, Cramer KE. Pilon fractures. Treatment protocol based on severity of soft tissue injury. Clin Orthop Relat Res. 2000;375:78-90. https://doi. org/10.1097/00003086-200006000-00010

PMid: 10853156

16. Blauth M, Bastian L, Krettek C, Knop C, Evans S. Surgical options for the treatment of severe tibial pilon fractures: A study of three techniques. J Orthop Trauma. 2001;15(3):153-60. https://doi.org/10.1097/00005131-200103000-00002 PMid: 11265004

17. Helfet DL, Shonnard PY, Levine D, Borrelli J Jr. Minimally invasive plate osteosynthesis of distal fractures of the tibia.
Injury. 1997;28(Suppl

s0020-1383(97)90114-5

PMid:10897286

18. Ibrahim DA, Swenson A, Sassoon A, Fernando ND. Classifications in brief: The tscherne classification of soft tissue injury. Clin Orthop Relat Res. 2017;475(2):560-4. https://doi. org/10.1007/s11999-016-4980-3

PMid:27417853

19. Teeny SM, Wiss DA. Open reduction and internal fixation of tibial plafond fractures. Variables contributing to poor results and complications. Clin Orthop Relat Res. 1993;292:108-17. https://doi.org/10.1097/00003086-199307000-00013 PMid:8519097

20. Rüedi TP, Murphy WM. AO Principles of Fracture Management. New York, Stuttgart: Thieme; 2000.

21. Scolaro J, Ahn J. In brief: Pilon fractures. Clin Orthop Relat Res 2011;469(2):621-3. https://doi.org/10.1007/s11999-010-1509-z

22. Dillin L, Slabaugh P. Delayed wound healing, infection, and nonunion following open reduction and internal fixation of tibial plafond fractures. J Trauma. 1986;26(12):1116-9. https://doi. org/10.1097/00005373-198612000-00011

PMid:3795310

23. Wyrsch B, McFerran MA, McAndrew M, Limbird TJ, Harper MC, Johnson KD, et al. Operative treatment of fractures of the tibial plafond. A randomized, prospective study. J Bone Joint Surg Am. 1996;78(11):1646-57. https://doi. org/10.2106/00004623-199611000-00003

\section{PMid:8934478}

24. Patterson MJ, Cole JD. Two-staged delayed open reduction and internal fixation of severe pilon fractures. J Orthop Trauma. 1999;13(2):85-91. https://doi.org/ 10.1097/00005131-199902000-00003 PMid:10052781

25. Sirkin M, Sanders R, DiPasquale T, Herscovici D Jr. A staged protocol for soft tissue management in the treatment of complex pilon fractures. J Orthop Trauma. 1999;13(2):78-84. https://doi. org/10.1097/00005131-199902000-00002 PMid: 10052780

26. Liporace FA, Yoon RS. Decisions and staging leading to definitive open management of pilon fractures: Where have we come from and where are we now? J Orthop Trauma. 2012;26(8):488-98. https://doi.org/10.1097/bot.0b013e31822fbdbe PMid:22357091

27. Mehta S, Gardner MJ, Barei DP, Benirschke SK, Nork SE. Reduction strategies through the anterolateral exposure for fixation of Type B and C pilon fractures. J Orthop Trauma. 2011;25(2):116-22. https://doi.org/10.1097/ bot.0b013e3181cf00f3 PMid:21245716

28. McCann PA, Jackson M, Mitchell ST, Atkins RM. Complications of definitive open reduction and internal fixation of pilon fractures of the distal tibia. Int Orthop. 2011;35(3):413-8. https:// doi.org/10.1007/s00264-010-1005-9 PMid:20352430

29. Bear J, Rollick N, Helfet D. Evolution in management of tibia pilon fractures. Curr Rev Musculoskelet Med. 2018;11(4):53745. https://doi.org/10.1007/s12178-018-9519-7 PMid:30343399 